\title{
The characteristics and risk factors for cisplatin- induced acute kidney injury in the elderly
}

This article was published in the following Dove Press journal:

Therapeutics and Clinical Risk Management

\author{
Jie-qiong Liu', \\ Guang-yan Cai' \\ Si-yang Wang' \\ Yu-huan Song' \\ Yuan-yuan Xia' \\ Shuang Liang' \\ Wen-ling Wang' \\ Sa-sa Nie' \\ Zhe Feng' \\ Xiang-mei Chen' \\ 'Department of Nephrology, Chinese \\ PLA General Hospital, Chinese PLA \\ Institute of Nephrology, State Key \\ Laboratory of Kidney Diseases, \\ National Clinical Research Center \\ for Kidney Disease, Beijing, China; \\ ${ }^{2}$ Department of Nephrology, Chinese \\ PLA 40I Hospital, Qingdao, China
}

Correspondence: Guang-yan Cai Department of Nephrology, Chinese PLA General Hospital, 28 Fuxing Road, Beijing 100853, China

Tel +86 I0 66935462

Fax +86 1068130297

Email caiguangyan@sina.com
Objectives: The most serious adverse reaction of cisplatin is acute kidney injury (AKI). Cisplatin-induced acute kidney injury (CIA) has no specific preventive measures. This study aims to explore the characteristics and risk factors for CIA in the elderly and to identify potential methods to reduce CIA.

Materials and methods: Patients $\geq 18$ years old, with primary tumors, who received initial cisplatin chemotherapy and whose serum creatinine ( $\mathrm{SCr}$ ) values were measured within 2 weeks pre- and postcisplatin treatment and who had complete medical records, were selected from a single center from January 1, 2013 to December 31, 2015. The exclusion criteria included radiotherapy or surgery, recurrent tumors, previous cisplatin treatment, lack of any SCr values before or after cisplatin therapy, and incomplete medical records.

Results: Out of a total of 527 patients, 349 were elderly. Angiotensin-converting enzyme inhibitor/angiotensin receptor blocker (ACEI/ARB) use $(9.2 \%)$ was more prevalent in the elderly than in younger patients $(2.8 \%, p=0.007)$. The dosage of cisplatin treatment was lower in the elderly, but the incidence of CIA $(9.46 \%)$ was higher in the elderly than in younger patients $(3.37 \%)$. There were significant differences in the SCr levels, estimated glomerular filtration rate, ACEI/ARB use, and whether a single application of cisplatin was administered, between the elderly AKI group and the non-AKI group. Multivariable analysis showed that administration of a single application of cisplatin (OR 2.853, 95\% CI: 1.229, 6.621, $p=0.015$ ) and ACEI/ARB use (OR 3.398, 95\% CI: 1.352, 8.545, $p=0.009$ ) were predictive factors for developing CIA in the elderly.

Conclusion: The incidence of CIA in the elderly was higher than in younger patients. ACEI/ ARB usage and administration of a single application of cisplatin were independent risk factors for CIA in the elderly.

Keywords: cisplatin-induced acute kidney injury, elderly, clinical characteristics, risk factors

\section{Introduction}

Medication-induced acute kidney injury (AKI) is significant in the elderly; medications account for $\sim 20 \%$ of AKI among older patients. ${ }^{1}$ The aged population is susceptible to cancer. ${ }^{2}$ In the USA, most patients diagnosed with cancer are $\geq 65$ years old, and it has been predicted that from 2010 to 2030, the cancer incidence among the aged will increase by $67 \% .{ }^{3}$ Cisplatin is widely used for the treatment of various solid tumors, such as lung, esophageal, bladder, head, and neck cancers. ${ }^{4}$ Currently, according to the National Institutes of Health, more than 273,000 cancer-related clinical trials are being conducted worldwide, in which the majority of the tested drugs are cisplatinand platinum-based agents. ${ }^{5}$ However, cisplatin nephrotoxicity is observed in more than $30 \%$ of older patients, and cisplatin-induced acute kidney injury (CIA) is the most serious adverse reaction, which limits its use and efficacy in chemotherapy. ${ }^{6}$ 
Moreover, the mechanism of nephrotoxicity remains unclear. Although hydration and forced diuresis with diuretics or mannitol are the best-known and most common nephroprotective measures, other nephroprotective approaches are also being studied; however, the protective effects are not satisfactory. ${ }^{7,8}$ There is an urgent need for specific nephroprotective strategies to be used during cisplatin chemotherapy. Therefore, to prevent and reduce the incidence of CIA in the elderly, we investigated the characteristics of elderly patients with cisplatin chemotherapy and explored the risk factors for CIA in the elderly.

\section{Materials and methods}

All procedures followed were in accordance with the ethical standards of the Ethics Committee of Chinese PLA General Hospital (S2016-100-01) regarding human experimentation (institutional and national) and with the Helsinki Declaration of 1975, as revised in 2000. The ethics committee of the hospital waived the need for written informed consent from the patients because the study was retrospective.

We collected clinical information regarding inpatients in the Department of Oncology using the hospital's information system: age $\geq 18$ years initially diagnosed with primary cancer and received first cisplatin chemotherapy during the period from January 1, 2013 to December 31, 2015. Patients were excluded if they had undergone synchronous radiation therapy or surgery before cisplatin chemotherapy, were administered cisplatin plus other chemotherapy drugs in other hospitals, were diagnosed with recurrent cancer, or had incomplete medical records. If the patients' serum creatinine ( $\mathrm{SCr}$ ) levels were not obtained, either pre- or post-cisplatin treatment, they were also excluded. A flowchart demonstrating how patients were screened is shown in Figure 1. Demographic and treatment data, medical history, and laboratory test data were collected. The estimated glomerular filtration rate (eGFR) was calculated by the four-variable Chronic Kidney Disease Epidemiology Collaboration equation. ${ }^{9,10}$

CIA was defined as an increase in SCr levels $\geq 25 \%$ from the baseline within 30 days after the first cycle of cisplatin $^{11}$ or was determined using the AKI 2012 Kidney Disease: Improving Global Outcomes (KDIGO) criteria for each patient within 7 days after chemotherapy. ${ }^{12}$ To date, no hydration protocol has been established and followed universally for cancer patients, an no guidelines regarding optimal and minimal fluid volume during cisplatin chemotherapy have been established. ${ }^{13,14}$ In the current study, if patients received $\geq 1.5 \mathrm{~L}$ intravenous normal saline solution within 1 day before cisplatin treatment, they were considered to have received hydration. Not all patients received oral rehydration.

The quantitative variables are presented as the means $\pm \mathrm{SD}$ or medians (25\%, 75\% quartile). Qualitative data are described as $n(\%)$. Groups were compared with analysis of variance or Student's $t$-test and chi-square test, with continuous or categorical variables, as appropriate. Logistic regression analysis was used to explore the associated risk factors for CIA in the elderly. All statistical analyses were performed with SPSS 19.0 (IBM Corporation, Armonk, NY, USA). A $p$-value of $<0.05$ was considered statistically significant.

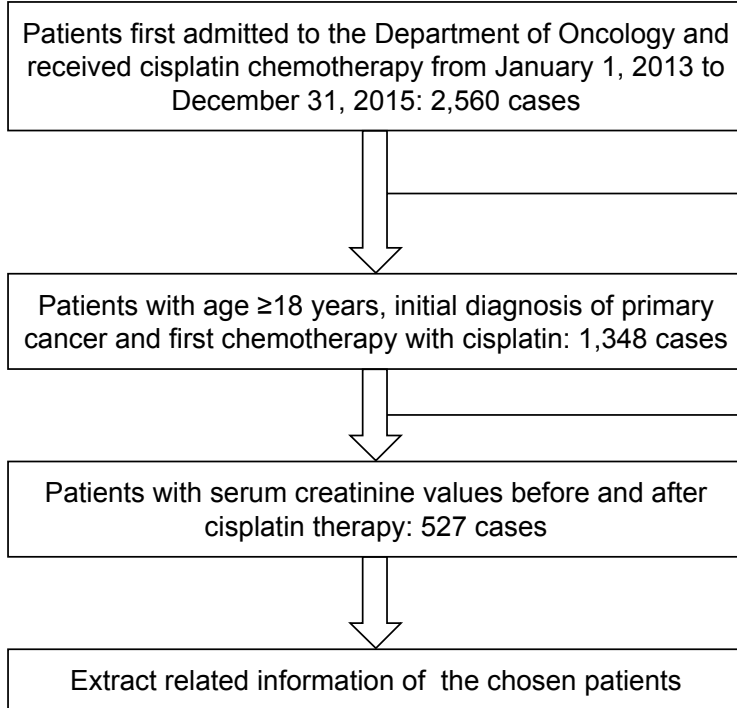

Figure I The flowchart of patient screening
Exclusion criteria

Recurrent cancer: 259 cases

Chemotherapy of postoperation or synchronous radiotherapy: 485 cases Chemotherapy with cisplatin or other drugs in other hospitals: 430 cases Age $<18$ years: 33 cases

Incomplete medical records: 5 cases

\section{Exclusion criteria}

Lack of serum creatinine value pre- or postcisplatin therapy: 821 cases 


\section{Results}

Five hundred and twenty-seven patients were chosen for this study, 349 of whom were $\geq 60$ years old. Patients' demographic and general information are shown in Table 1. CIA was observed in $33(9.46 \%)$ of the 349 enrolled elderly patients; however, six (3.37\%) of the 178 younger patients were also diagnosed with CIA. The incidence of CIA was significantly higher in the elderly than in the younger group ( $p=0.012)$. In Table 1, the baseline characteristics of the older patients showed that the majority of patients were men $(79.1 \%)$, and the mean age was 61.7 years.
Concurrent diseases, including hypertension, diabetes mellitus, and cardio-cerebrovascular disease, were more common in the elderly than in younger patients. Angiotensin-converting enzyme inhibitor/angiotensin receptor blocker (ACEI/ARB) medication was more frequently used in the older patients $(9.2 \%)$ than in the younger patients $(2.8 \%, p=0.007)$. In terms of laboratory tests, hemoglobin (130.95 vs $133.98 \mathrm{~g} / \mathrm{L})$, serum protein ( 66.18 vs $67.85 \mathrm{~g} / \mathrm{L}$ ), and albumin (38.31 vs $40.69 \mathrm{~g} / \mathrm{L}$ ) levels of the older group were lower than those of the younger group $(p<0.05)$. However, $\mathrm{SCr}$ and blood urea nitrogen levels were higher, and the subsequent mean

Table I Clinical characteristics of cancer patients who received cisplatin treatment

\begin{tabular}{|c|c|c|c|c|}
\hline Characteristics & $\begin{array}{l}\text { Total } \\
(n=527)\end{array}$ & $\begin{array}{l}\text { Elderly } \\
(n=349)\end{array}$ & $\begin{array}{l}\text { Nonelderly } \\
(n=178)\end{array}$ & $p$-value \\
\hline Age (years) & $61.71 \pm 10.86$ & $68.25 \pm 3.97$ & $48.90 \pm 8.32$ & $<0.001$ \\
\hline Male n (\%) & $399(75.7 \%)$ & $276(79.1 \%)$ & $123(69.1 \%)$ & 0.011 \\
\hline ACEI/ARBs & $37(7.0 \%)$ & $32(9.2 \%)$ & $5(2.8 \%)$ & 0.007 \\
\hline NSAIDs & $20(3.8 \%)$ & $12(3.4 \%)$ & $8(4.5 \%)$ & 0.310 \\
\hline CKD & $16(3.0 \%)$ & $14(4.0 \%)$ & $2(1.1 \%)$ & 0.104 \\
\hline Hypertension & $122(23.1 \%)$ & $100(28.7 \%)$ & $22(12.4 \%)$ & $<0.001$ \\
\hline DM & 65 (I2.3\%) & $56(16.0 \%)$ & $9(5.1 \%)$ & 0.001 \\
\hline Cardio-cerebrovascular disease & $72(13.7 \%)$ & 67 (19.2\%) & $5(2.8 \%)$ & $<0.001$ \\
\hline $\mathrm{BMI}\left(\mathrm{Kg} / \mathrm{m}^{2}\right)$ & $23.64 \pm 3.28$ & $23.62 \pm 3.30$ & $23.70 \pm 3.24$ & 0.528 \\
\hline $\mathrm{SBP}(\mathrm{mmHg})$ & $125.50 \pm 13.25$ & $126.63 \pm 13.42$ & $|23.4| \pm 13.67$ & $<0.001$ \\
\hline $\mathrm{DBP}(\mathrm{mmHg})$ & $76.13 \pm 7.52$ & $75.94 \pm 7.58$ & $76.5 I \pm 7.4 I$ & 0.732 \\
\hline $\mathrm{Hb}(\mathrm{g} / \mathrm{L})$ & $131.00 \pm 19.02$ & $130.95 \pm 18.44$ & $133.98 \pm 19.13$ & 0.027 \\
\hline $\mathrm{SCr}(\mu \mathrm{mol} / \mathrm{L})$ & $71.57 \pm 15.13$ & $73.20 \pm 15.16$ & $68.43 \pm 14.60$ & $<0.001$ \\
\hline eGFR (mL/min) & $92.37 \pm 14.54$ & $88.81 \pm 10.33$ & $99.74 \pm 13.15$ & 0.014 \\
\hline BUN (mmol/L) & $4.77 \pm 1.72$ & $5.00 \pm 1.73$ & $4.32 \pm 1.60$ & $<0.001$ \\
\hline SUA ( $\mu \mathrm{mol} / \mathrm{L})$ & $295.32 \pm 90.23$ & $292.98 \pm 90.14$ & $298.70 \pm 89.22$ & 0.478 \\
\hline Total protein $(\mathrm{g} / \mathrm{L})$ & $66.75 \pm 5.84$ & $66.18 \pm 6.05$ & $67.85 \pm 5.18$ & 0.001 \\
\hline ALB $(g / L)$ & $39.11 \pm 4.32$ & $38.31 \pm 4.14$ & $40.69 \pm 4.23$ & $<0.001$ \\
\hline $\mathrm{Na}(\mathrm{mmol} / \mathrm{L})$ & I $42.00(|39.90$,$| I43.06)$ & $|4| .20(|38.70| 43.20)$, & $14 \mid .90(|39.93| 43.38)$, & 0.710 \\
\hline $\mathrm{K}(\mathrm{mmol} / \mathrm{L})$ & $4.12 \pm 0.43$ & $5.31 \pm 0.49$ & $4.13 \pm 0.38$ & 0.685 \\
\hline $\mathrm{Mg}(\mathrm{mmol} / \mathrm{L})$ & $0.90 \pm 0.08$ & $0.89 \pm 0.08$ & $0.89 \pm 0.68$ & 0.879 \\
\hline Cisplatin total dose (mg) & $114.95 \pm 25.57$ & $112.42 \pm 22.90$ & $119.90 \pm 24.17$ & 0.001 \\
\hline Cisplatin mean dose $\left(\mathrm{mg} / \mathrm{m}^{2}\right)$ & $66.53 \pm 13.16$ & $64.32 \pm 25.93$ & $69.34 \pm 11.22$ & $<0.001$ \\
\hline Cisplatin frequency & & & & 0.720 \\
\hline Single & $329(62.4 \%)$ & $215(61.6 \%)$ & II 4 (64.0\%) & \\
\hline$\geq$ Two times & $198(37.6 \%)$ & $134(38.4 \%)$ & $64(36.0 \%)$ & \\
\hline Cisplatin application & & & & 0.408 \\
\hline I.V. & 481 (9l.3\%) & $316(90.5 \%)$ & $165(92.7 \%)$ & \\
\hline Non-I.V. & $46(8.7 \%)$ & $33(9.5 \%)$ & $13(7.3 \%)$ & \\
\hline Hydration & 491 (93.2\%) & $327(93.7 \%)$ & $164(92.1 \%)$ & 0.668 \\
\hline Volume of hydration $(\mathrm{mL})$ & $2,4 \mid 2.56 \pm 846.08$ & $2,432.01 \pm 839.57$ & $2,374.44 \pm 859.79$ & 0.305 \\
\hline Diuretics & $34 \mathrm{I}(64.7 \%)$ & $223(63.9 \%)$ & 118 (66.3\%) & 0.890 \\
\hline $\mathrm{ClA}$ & $39(7.4 \%)$ & $33(9.46 \%)$ & $6(3.37 \%)$ & 0.012 \\
\hline Stage I CIA & $32(6.1 \%)$ & $26(7.5 \%)$ & $6(3.4 \%)$ & 0.054 \\
\hline Stage $2 \mathrm{CIA}$ & $5(0.9 \%)$ & $5(1.4 \%)$ & 0 & \\
\hline Stage $3 \mathrm{CIA}$ & $2(0.4 \%)$ & $2(0.6 \%)$ & 0 & \\
\hline
\end{tabular}

Note: $p$-value $<0.05$ was considered statistically significant.

Abbreviations: ACEI/ARBs, angiotensin-converting enzyme inhibitor/angiotensin receptor blockers; BMI, body mass index; BUN, blood urea nitrogen; CKD, chronic kidney disease; DBP, diastolic blood pressure; DM, diabetes mellitus; eGFR, estimated glomerular filtration rate; I.V., intravenous injection; K, serum potassium; Mg, serum magnesium; Na, serum sodium; NSAIDs, nonsteroidal anti-inflammatory drugs; SCr, serum creatinine; SUA, serum uric acid; ALB, albumin; SBP, systolic blood pressure. 
Table 2 Baseline clinical characteristics of cisplatin-induced AKI in the elderly

\begin{tabular}{|c|c|c|c|c|}
\hline Characteristics & $\begin{array}{l}\text { Elderly } \\
(\mathrm{n}=349)\end{array}$ & $\begin{array}{l}\text { AKI } \\
(n=33)\end{array}$ & $\begin{array}{l}\text { Non-AKI } \\
(n=316)\end{array}$ & $p$-value \\
\hline Age (years) & $68.25 \pm 3.97$ & $67.45 \pm 2.79$ & $68.33 \pm 4.07$ & 0.109 \\
\hline Sex & & & & 0.345 \\
\hline Male & $276(79.1 \%)$ & $24(72.7 \%)$ & $252(79.7 \%)$ & \\
\hline Female & $73(20.9 \%)$ & $9(27.3 \%)$ & $64(20.3 \%)$ & \\
\hline BMI $\left(m g / m^{2}\right)$ & $23.62 \pm 3.30$ & $24.26 \pm 3.64$ & $23.54 \pm 3.26$ & 0.235 \\
\hline DM & $56(16 \%)$ & $6(18.2 \%)$ & $50(15.8 \%)$ & 0.725 \\
\hline Hypertension & $100(28.7 \%)$ & $12(36.4 \%)$ & $88(27.8 \%)$ & 0.303 \\
\hline CKD & $14(4.0 \%)$ & I (3.0\%) & $13(4.1 \%)$ & 1.0 \\
\hline Cardio-cerebrovascular disease & 67 (19.2\%) & $6(18.2 \%)$ & $61(19.3 \%)$ & 0.876 \\
\hline NSAIDs & $12(3.4 \%)$ & $12(3.8 \%)$ & 0 & \\
\hline ACEl/ARBs & 32 (9.2\%) & 7 (2I.2\%) & $25(8.15 \%)$ & 0.014 \\
\hline Hydration & 327 (93.7\%) & $32(97 \%)$ & 29 (93.4\%) & 0.416 \\
\hline Volume of hydration (mL) & $2,595.63 \pm 57 \mid .35$ & $2,550.0 \pm 544.62$ & $2,600.0 \pm 574.85$ & 0.696 \\
\hline Diuretics & $223(63.9 \%)$ & $25(75.8 \%)$ & $198(62.7 \%)$ & 0.136 \\
\hline Cisplatin total dose (mg) & $116.28 \pm 20.67$ & $115.76 \pm 25.38$ & I $12.07 \pm 26.00$ & 0.325 \\
\hline Cisplatin mean dose $\left(\mathrm{mg} / \mathrm{m}^{2}\right)$ & $67.31 \pm 10.57$ & $67.14 \pm 13.57$ & $65.05 \pm 13.73$ & 0.145 \\
\hline Single-use cisplatin & $215(61.6 \%)$ & $188(59.5 \%)$ & 27 (8.54\%) & 0.012 \\
\hline I.V. cisplatin & $316(90.5 \%)$ & 31 (93.9\%) & $285(90.2 \%)$ & 0.484 \\
\hline $\mathrm{SCr}(\mu \mathrm{mol} / \mathrm{L})$ & $73.18 \pm 15.16$ & $74.02 \pm 14.96$ & $65.19 \pm 14.99$ & 0.001 \\
\hline eGFR (mL/min) & $86.82 \pm 12.11$ & $86.24 \pm|2.2|$ & $92.71 \pm 12.31$ & 0.002 \\
\hline Total protein $(g / L)$ & $66.18 \pm 6.05$ & $67.15 \pm 5.69$ & $66.08 \pm 6.07$ & 0.335 \\
\hline ALB $(g / L)$ & $38.31 \pm 4.14$ & $37.89 \pm 4.15$ & $38.35 \pm 4.14$ & 0.546 \\
\hline $\mathrm{Na}(\mathrm{mmol} / \mathrm{L})$ & $140.56 \pm 4.42$ & $139.42 \pm 5.42$ & $|40.67 \pm 4.3|$ & 0.052 \\
\hline $\mathrm{K}(\mathrm{mmol} / \mathrm{L})$ & $3.99 \pm 0.51$ & $3.94 \pm 0.39$ & $3.98 \pm 0.52$ & 0.661 \\
\hline $\mathrm{Mg}(\mathrm{mmol} / \mathrm{L})$ & $0.89 \pm 0.08$ & $0.88 \pm 0.07$ & $0.90 \pm 0.08$ & 0.126 \\
\hline
\end{tabular}

Note: $p$-value $<0.05$ was considered statistically significant.

Abbreviations: ACEI/ARBs, angiotensin-converting enzyme inhibitor/angiotensin receptor blockers; AKI, acute kidney injury; BMI, body mass index; CKD, chronic kidney disease; DM, diabetes mellitus; eGFR, estimated glomerular filtration rate; I.V., intravenous injection; K, serum potassium; Mg, serum magnesium; Na, serum sodium; NSAIDs, nonsteroidal anti-inflammatory drugs; $\mathrm{SCr}$, serum creatinine; $\mathrm{ALB}$, albumin.

eGFR was lower in the elderly compared with the younger group. The cisplatin total dose and the cisplatin mean dose, according to the body surface area, were smaller for the elderly than for younger patients. Nevertheless, there were no significant differences between the elderly and nonelderly groups in cisplatin frequency, intravenous application, hydration, and diuretic use.

Next, the baseline characteristics of older CIA patients were analyzed and compared with those of non-AKI older patients, as shown in Table 2. There were significant differences between the two groups only in ACEI/ARB use, the administration of a single cisplatin application, $\mathrm{SCr}$ levels, and eGFR. In the AKI group, $21.2 \%$ of the patients used ACEI/ARBs, whereas 8.1\% used ACEI/ARBs in the non-AKI group ( $p=0.014$ ). Of the CIA patients, $59.5 \%$ were administered cisplatin once, but only $8.54 \%$ received a single cisplatin treatment in the non-AKI group ( $p=0.012)$. The baseline mean SCr level was 74.02 $\pm 14.96 \mu \mathrm{mol} / \mathrm{L}$ in the AKI group and $65.19 \pm 14.99 \mu \mathrm{mol} / \mathrm{L}$ in the non-AKI group $(p=0.001)$. As a result, the baseline mean eGFRs for the
AKI group and the non-AKI group were $86.24 \pm 12.21$ and $92.71 \pm 12.31 \mathrm{~mL} / \mathrm{min} / 1.73 \mathrm{~m}^{2}$, respectively $(p=0.002)$.

In the univariate logistic regression analysis, we identified ACEI/ARB use (OR 3.340, 95\% CI: 1.361, 8.192, $p=0.008$ ) and the single administration of cisplatin (OR 3.064, 95\% CI: $1.230,7.632, p=0.016)$ as associated predictors of CIA in the elderly (Table 3$)$. The baseline eGFR $(p=1.065)$ and the age of the elderly ( $p=0.227$ ) were not significantly associated with CIA. Finally, multivariate logistic regression analyses were performed and revealed that ACEI/ARB use (OR 3.398, 95\% CI: 1.352, 8.545, $p=0.009$ ) and the single administration of cisplatin (OR 2.853, 95\% CI: 1.229, 6.621, $p=0.015)$ were independent risk factors for developing CIA in the elderly.

\section{Discussion}

Cisplatin is a nonspecific cytotoxic agent that primarily interferes with cellular DNA replication and the cell cycle, but lacks selectivity. Therefore, it also acts on normal cells and easily causes adverse reactions, especially AKI. However, 
Table 3 Risk factors for cisplatin-induced AKI in the elderly

\begin{tabular}{|c|c|c|c|c|}
\hline \multirow[t]{2}{*}{ Risk factors } & \multicolumn{2}{|c|}{ Univariable analysis } & \multicolumn{2}{|c|}{ Multivariable analysis } \\
\hline & OR (95\% Cl) & $p$-value & OR $(95 \% \mathrm{Cl})$ & $p$-value \\
\hline Age ( $\geq 60$ years) & $0.943(0.858,1.037)$ & 0.227 & $0.985(0.883,1.098)$ & 0.785 \\
\hline Baseline eGFR & $0.958(0.932,0.984)$ & 1.065 & $0.975(0.930,1.023)$ & 0.302 \\
\hline ACEI/ARBs use & 3.340 (I.36I, 8.192) & 0.008 & $3.398(1.352,8.545)$ & 0.009 \\
\hline Cisplatin single application & $3.064(1.230,7.632)$ & 0.016 & $2.853(1.229,6.621)$ & 0.015 \\
\hline
\end{tabular}

Note: $p$-value $<0.05$ was considered statistically significant.

Abbreviations: ACEI/ARBs, angiotensin-converting enzyme inhibitor/angiotensin receptor blockers; AKI, acute kidney injury; eGFR, estimated glomerular filtration rate.

the exact mechanism of cisplatin nephrotoxicity remains unclear. The traditional preventive methods, such as reducing the drug dosage and administering aggressive hydration, have not been succesful. ${ }^{8,13,14}$ To date, there are no guidelines for a standardized, simple definition of CIA. A systematic review that included 24 studies showed that the definitions of cisplatin-induced kidney injury varied across studies. ${ }^{15}$ Therefore, the incidence of CIA in the literature is diverse.

We defined CIA as an increase in the SCr level $\geq 25 \%$ of baseline or used the 2012 KDIGO criteria for the first cisplatin chemotherapy cycle; we opted for this definition for several reasons. First, because of the retrospective nature of this study, it was not easy to obtain values for timed $\mathrm{SCr}$ levels and urine volume. Second, Mizuno et al found that the KDIGO criteria could be useful predictors of CIA mortality in patients with different primary cancers, ${ }^{12}$ and Latcha et al confirmed that an increase in SCr levels $\geq 25 \%$ is not insignificant and is associated with chronic kidney disease (CKD) in a long-term follow-up study. ${ }^{11}$ Third, this criterion ruled out the interference of more cisplatin chemotherapy cycles.

In this study, the incidence of CIA in the elderly was $9.46 \%$, which was higher than that in younger patients. This is consistent with previous experimental and clinical studies. ${ }^{16,17}$ The older patient is susceptible to nephrotoxicity, due to specific anatomical and functional changes, including kidney vasculature, filtration, and tubulointerstitial function. ${ }^{18}$ However, we did not find that age and renal function were independent risk factors for CIA in the elderly. Previous studies had similar results. ${ }^{19}$ Recently, Lavolé et al also found no association between age and cisplatin nephrotoxicity, and most patients experienced grade $1 \mathrm{CIA} .{ }^{20}$ Therefore, cancer patients requiring cisplatin treatment should not be refused based on age or moderate, age-related renal dysfunction.

ACEI/ARB usage was an independent risk factor for CIA in the elderly. ACEI/ARBs are commonly used for several chronic conditions, such as hypertension, CKD, diabetic nephropathy, and congestive heart failure. With the increasing prevalence of these chronic conditions in the older population, ACEI/ARBs are more commonly used for the elderly. ${ }^{1}$ Almanric et al showed that ACEI/ARBs were used in 29/80 patients (36\%), and taking an ACEI or an ARB resulted in an increase of $12.1 \mu \mathrm{mol} / \mathrm{L}$ (95\% CI: $-15.0,39.2)$ in the SCr level, but this increase was found to be statistically insignificant in a multivariate linear and logistic regression analyses. ${ }^{21}$ This result was different from our study. This difference may be explained by the possibility that the CIA criteria were different in each study, or that the research population only with stage 4 nonsmall-cell lung cancer or with different tumor types was different. ACEI/ARBs can cause the vasodilation of both afferent and efferent arterioles, but the effect is more significant in the latter, ${ }^{22}$ which can interfere with the renal autoregulation of the GFR; the resulting aggravated renal ischemia constitutes a higher risk for AKI. Moreover, studies have shown that plasma renin activity and plasma aldosterone concentration are elevated after cisplatin administration, which also results in GFR decline. ${ }^{23}$ ACEI/ARBs may suppress the activity of the renin-angiotensin system that maintains the GFR, aggravating kidney ischemia and delaying cisplatin excretion. ${ }^{24}$ Recently, a clinical study also found that ACEI use was associated with renal toxicity during platinumbased chemoradiation. ${ }^{25}$ Therefore, the discontinuation of ACEI/ARBs use should be suggested when patients undergo chemotherapy with cisplatin.

CIA in the elderly was positively associated with a single cisplatin dose administered in 1 day. Several studies have shown that cisplatin treatment divided into smaller doses and administered over several days was effective and well tolerated. ${ }^{26,27}$ Espeli et al found that weekly cisplatin chemotherapy had less adverse effects than a 3-weekly regimen. ${ }^{28}$ Lavolé et al investigated the rapid outpatient administration of a single dose of cisplatin at $\geq 75 \mathrm{mg} / \mathrm{m}^{2}$ and found that it was feasible, without a high risk of nephrotoxicity, ${ }^{20}$ which is in accordance with our study. However, they found that cisplatin at a dose $\geq 100 \mathrm{mg} / \mathrm{m}^{2}$ during the first cycle $(\mathrm{HR}=9.5, \mathrm{CI}=3.2-28)$ was an independent risk factor predictive of nephrotoxicity. 
However, in our study, the dose of cisplatin was not associated with CIA. This was possibly related to the smaller dose, but a further prospective study is required to verify this hypothesis. Recently, a meta-analysis revealed that a weekly low-dose regimen had increased compliance and significantly less toxicity than a 3-weekly high-dose regimen. ${ }^{29}$ It is known that an increased incidence of cisplatin-induced acute nephrotoxicity is related to high-peak plasma-free platinum concentrations $\left(\mathrm{C}_{\max }\right) .{ }^{30}$ The nephrotoxic effect of cisplatin, which accumulates in the kidneys, is proportional to the amount of the drug that is accumulated. ${ }^{31}$ Two to 5 days of successive cisplatin administration, as opposed to the 1-day administration of a given total dose, can reduce cisplatin nephrotoxicity. ${ }^{32}$ Therefore, older patients should avoid 1-day, single administration of cisplatin to reduce CIA.

The present study had a few limitations. First, because of the retrospective nature of this study in a single institution and a potential patient selection bias, a multi-center, large-scaled, prospective study is needed to confirm these results and to ensure the generalizability of our data. Second, patients with different tumor types may be heterogeneous due to different tumor staging and severity grades. Third, we need to further assess the role of hydration, including oral hydration, because we only considered intravenous hydration due to our inability to obtain questionnaires regarding the volume of oral hydration.

\section{Conclusion}

The incidence of CIA in the elderly was higher than that in contemporary younger patients. We identified the single administration of cisplatin and ACEI/ARBs use as independent risk factors for developing CIA in the elderly.

\section{Author contributions}

All authors contributed toward data analysis, drafting and critically revising the paper and agree to be accountable for all aspects of the work.

\section{Acknowledgments}

This work was supported by the 973 program (2013CB530800), the Twelfth Five-Year National Key Technology Research and Development Program (2015BAI12B06, 2013BAI09B05), the 863 program (2012AA02A512), and the National Nature Science Foundation of China (81670694, 81401160, 81070267). The authors gratefully acknowledge Professor Shun-chang Jiao, Yi Hu and Guang-hai Dai (Department of Oncology, Chinese PLA General Hospital, Beijing, China) for providing data.

\section{Disclosure}

The authors report no conflicts of interest in this work.

\section{References}

1. Fusco S, Garasto S, Corsonello A, et al. Medication-induced nephrotoxicity in older patients. Curr Drug Metab. 2016;6(17):608-625.

2. Smetana K Jr, Lacina L, Szabo P, Dvořánková B, et al. Ageing as an important risk factor for cancer. Anticancer Res. 2016;36(10):5009-5017.

3. Smith BD, Smith GL, Hurria A, et al. Future of cancer incidence in the United States: burdens upon an aging, changing nation. J Clin Oncol. 2009;27(17):2758-2765.

4. Ohmichi M, Hayakawa J, Tasaka K, Kurachi H, Murata Y. Mechanisms of platinum drug resistance. Trends Pharmacol Sci. 2005;26(3): 113-116.

5. National Institutes of Health. Clinical Trials Database. Available from: https://www.clinicaltrials.gov. Accessed May 21, 2018.

6. Hanigan MH, Devarajan P. Cisplatin nephrotoxicity: molecular mechanisms. Cancer Ther. 2003;1:47-61.

7. Pabla N, Dong Z. Cisplatin nephrotoxicity: mechanisms and renoprotective strategies. Kidney Int. 2008;73(9):994-1007.

8. Manohar S, Leung N. Cisplatin nephrotoxicity: a review of the literature. J Nephrol. 2018;31(1):15-25.

9. Kilbride HS, Stevens PE, Eaglestone G, et al. Accuracy of the MDRD (Modification of Diet in Renal Disease) study and CKD-EPI (CKD Epidemiology Collaboration) equations for estimation of GFR in the elderly. Am J Kidney Dis. 2013;61(1):57-66.

10. Michels WM, Grootendorst DC, Verduijn M, et al. Performance of the Cockcroft-Gault, MDRD, and new CKD-EPI formulas in relation to GFR, age, and body size. Clin J Am Soc Nephrol. 2010;5(6): 1003-1009.

11. Latcha S, Jaimes EA, Patil S, et al. Long-term renal outcomes after cisplatin treatment. Clin J Am Soc Nephrol. 2016;11(7):1173-1179.

12. Mizuno T, Sato W, Ishikawa K, et al. KDIGO (Kidney Disease: Improving Global Outcomes) criteria could be a useful outcome predictor of cisplatin-induced acute kidney injury. Oncology. 2012;82(6):354-359.

13. Máthé $\mathrm{C}$, Bohács $\mathrm{A}$, Duffek L, et al. Cisplatin nephrotoxicity aggravated by cardiovascular disease and diabetes in lung cancer patients. Eur Respir J. 2011;37(4):888-894.

14. Ninomiya K, Hotta K, Hisamoto-Sato A, et al. Short-term low-volume hydration in cisplatin-based chemotherapy for patients with lung cancer: the second prospective feasibility study in the Okayama Lung Cancer Study Group Trial 1201. Int J Clin Oncol. 2016;21(1):81-87.

15. Crona DJ, Faso A, Nishijima TF, et al. A systematic review of strategies to prevent cisplatin-induced nephrotoxicity. Oncologist. 2017;22(5): 609-619.

16. Espandiari P, Rosenzweig B, Zhang J, et al. Age-related differences in susceptibility to cisplatin-induced renal toxicity. J Appl Toxicol. 2010; 30(2):172-182

17. Wen J, Zeng M, Shu Y, et al. Aging increases the susceptibility of cisplatin-induced nephrotoxicity. Age (Dordr). 2015;37(6):112.

18. Rosner MH. Acute kidney injury in the elderly. Clin Geriatr Med. 2013; 29(3):565-578.

19. Hrushesky WJ, Shimp W, Kennedy BJ. Lack of age-dependent cisplatin nephrotoxicity. Am J Med. 1984;76(4):579-584.

20. Lavolé A, Danel S, Baudrin L, et al. Routine administration of a single dose of cisplatin $\geq 75 \mathrm{mg} / \mathrm{m}^{2}$ after short hydration in an outpatient lungcancer clinic. Bull Cancer. 2012;99(4):E43-E48.

21. Almanric K, Marceau N, Cantin A, Bertin É. Risk factors for nephrotoxicity associated with cisplatin. Can J Hosp Pharm. 2017;70(2): 99-106.

22. Palmer BF. Renal dysfunction complicating the treatment of hypertension. $N$ Engl J Med. 2002;347(16):1256-1261.

23. Kurt E, Manavoglu O, Dilek K, Orhan B, Evrensel T. Effect of cisplatin on plasma renin activity and serum aldosterone levels. Clin Nephrol. 1999;52(6):397-398. 
24. Komaki K, Kusaba T, Tanaka M, et al. Lower blood pressure and risk of cisplatin nephrotoxicity: a retrospective cohort study. BMC Cancer. 2017;17(1):144.

25. Spiotto MT, Cao H, Mell L, Toback FG. ACE inhibitors predict for acute kidney injury during chemoradiation for head and neck cancer. Anticancer Drugs. 2015;26(3):343-349.

26. Rades D, Seidl D, Janssen S, et al. Chemoradiation of locally advanced squamous cell carcinoma of the head-and-neck (LASCCHN): is $20 \mathrm{mg} / \mathrm{m}^{2}$ cisplatin on five days every four weeks an alternative to $100 \mathrm{mg} / \mathrm{m}^{2}$ cisplatin every three weeks? Oral Oncol. 2016;59:67-72.

27. Utkan G, Büyükçelik A, Yalçin B, et al. Divided dose of cisplatin combined with gemcitabine in malignant mesothelioma. Lung Cancer. 2006; 53(3):367-374.

28. Espeli V, Zucca E, Ghielmini M, et al. Weekly and 3-weekly cisplatin concurrent with intensity-modulated radiotherapy in locally advanced head and neck squamous cell cancer. Oral Oncol. 2012;48(3): 266-271.
29. Szturz P, Wouters K, Kiyota N, et al. Weekly low-dose versus threeweekly high-dose cisplatin for concurrent chemoradiation in locoregionally advanced non-nasopharyngeal head and neck cancer: a systematic review and meta-analysis of aggregate data. Oncologist. 2017;22(9): 1056-1066.

30. Reece PA, Stafford I, Russell J, Khan M, Gill PG. Creatinine clearance as a predictor of ultrafilterable platinum disposition in cancer patients treated with cisplatin: relationship between peak ultrafilterable platinum plasma levels and nephrotoxicity. J Clin Oncol. 1987;5(2):304-309.

31. Arany I, Safirstein RL. Cisplatin nephrotoxicity. Semin Nephrol. 2003; 23(5):460-464.

32. Cavaletti G, Tredici G, Pizzini G, Minoia A. Tissue platinum concentrations and cisplatin schedules. Lancet. 1990;336(8721):1003-1004.
Therapeutics and Clinical Risk Management

\section{Publish your work in this journal}

Therapeutics and Clinical Risk Management is an international, peerreviewed journal of clinical therapeutics and risk management, focusing on concise rapid reporting of clinical studies in all therapeutic areas outcomes, safety, and programs for the effective, safe, and sustained use of medicines. This journal is indexed on PubMed Central, CAS,

\section{Dovepress}

EMBase, Scopus and the Elsevier Bibliographic databases. The manuscript management system is completely online and includes a very quick and fair peer-review system, which is all easy to use. Visit http://www.dovepress.com/testimonials.php to read real quotes from published authors.

Submit your manuscript here: http://www.dovepress.com/therapeutics-and-clinical-risk-management-journal 